\title{
Multifocal calcifying fibrous tumor mimicking malignancy
}

\author{
Binita Goyal \\ Dept. of Pathology, College of Medical Sciences, Bharatpur
}

Correspondence
Dr. Binita Goyal
Dept. of Pathology,
College of Medical Sciences,
Bharatpur
Email: binitagoyal@yahoo.com

DOI: http://dx.doi.org/10.3126/ jemsn.v12i2.14677

Article received: March $21^{\text {st }} 2016$ Article accepted: June $1^{\text {st }} 2016$

\begin{abstract}
Calcifying fibrous tumor synonymous with calcifying fibrous pseudotumor is a rare benign mesenchymal tumor, recently been described in soft tissues. It is believed to be a true neoplasm with a tendency for nondestructive local recurrence. It presents as a single or multifocal well circumscribed but unencapsulated mass with variable size and may infiltrate into surrounding tissue. It is characterized histologically by hyalinized collagenous fibrous tissue, with bland spindle cells, psammomatous or dystrophic calcifications, and focal lymphoplasmacytic infiltrate. We present a rare case of multifocal calcifying fibrous tumors in retroperitoneum and in right adnexa in a 32-year-old female patient who presenting with pain in left lower abdomen. Imaging revealed large calcified solid mass lesion in right posterior para-renal space infiltrating into segment VI of liver and a similar smaller calcified mass in right adnexa which was confused with malignancy.

Key words: Calcifying fibrous tumor, fibrous tumor, multifocal
\end{abstract}

Citation: Goyal B. Multifocal calcifying fibrous tumor mimicking malignancy. JCMS Nepal. 2016 ; 12 (2):78-80.

\section{INTRODUCTION}

Calcifying fibrous tumor (CFT) synonymous with calcifying fibrous pseudotumor is a recently described uncommon benign fibrous lesion of soft tissue origin characterized by scattered fibroblasts, dense collagenization, abundant dystrophic and psammomatous calcifications and focal lymphoplasmacytic aggregates. ${ }^{1,2}$ This entity has been reported so far as single cases or small case series in various locations like subcutaneous tissue and deep soft tissues of extremities, neck, scrotum, mesentry, peritoneum, pleura, retroperitoneum and gastrointestinal tract. ${ }^{1-8}$ So far, to the best of our knowledge, only six cases of multifocal CFTs have been reported, mostly in peritoneum and pleura but none in retroperitoneum. ${ }^{3,4,8-11}$ We report a case of multifocal calcifying fibrous tumor in retroperitoneum and right adnexa in a 32-year-old female patient.

\section{CASE REPORT}

A 32-year-old female patient presented with pain in left lower abdomen for seven days which was nonradiating, dull aching in nature with no aggravating and relieving factors. There was no previous history of trauma or any other abdominal surgery in the past. There was no significant weight loss. Bladder, bowel habit and menstrual history were normal. Local examination revealed a mildly tender hard lump palpable over right flank region. Abdominal examination revealed tenderness in right flank region and right iliac fossa region on deep palpation. Other general and systemic examinations were normal. Ultrasonography revealed a huge calcified mass posterior to right kidney resulting in its displacement measuring $16.0 \times 9.0 \mathrm{~cm}$ and another calcified mass of $5.5 \times 4.0 \mathrm{~cm}$ in right adnexa. CECT of abdomen and pelvis showed a large extensively calcified hypodense soft tissue mass lesion, measuring approximately 16.8 x $10.3 \mathrm{x}$ $8.3 \mathrm{~cm}$ (cranio-caudal $\mathrm{x}$ transverse $\mathrm{x}$ anteroposterior) in right posterior pararenal space displacing the right kidney anteriorly which appeared to infiltrate the segment VI of right lobe of liver and another similar calcified mass lesion, measuring approximately $5.3 \times 3.4$ x $3.6 \mathrm{~cm}$ (cranio -caudal $x$ transverse $x$ antero-posterior) in right adnexa.

The patient underwent exploratory laparotomy and these masses were received for histopathological examination. Three multilobulated, well circumscribed but unencapsulated masses were received. Two were from retroperitoneum and measured $19.0 \times 12.0 \times 8.0 \mathrm{~cm}$ (Fig 1) and $7.0 \times 5.0$ $x 5.0 \mathrm{~cm}$ respectively. One was from right adnexa and measured $5.5 \times 3.0 \times 1.5 \mathrm{~cm}$. All three masses had whitish firm cut surface with yellowish-white hard areas (Fig 2). Histopathology from all the 


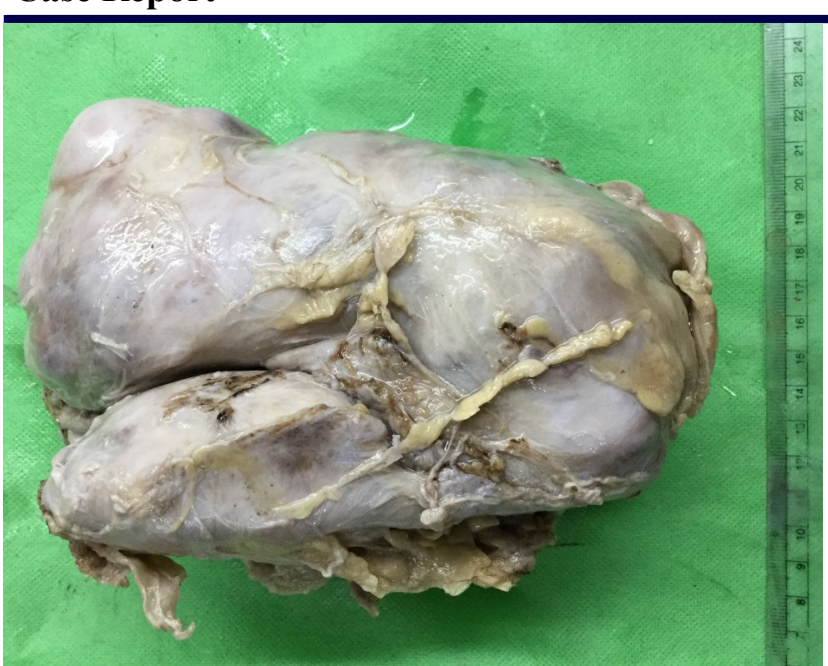

Fig 1: Gross picture showing largest mass in retroperitoneum

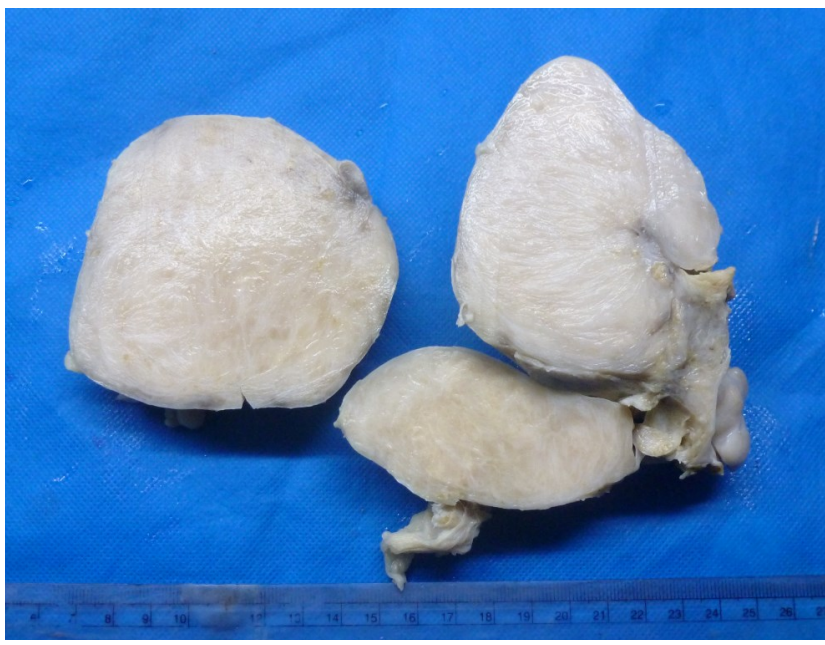

Fig 2: Cut section showing whitish firm areas

masses revealed circumscribed tumor tissue composed of predominantly hyalinized collagen bundles with few fascicles of fibroblasts with interspersed both dystrophic and pasammomatous calcifications and a lymphoplasmacytic infiltrate (Figs 3 and 4).

\section{DISCUSSION}

CFTs are benign, fibrous lesions of uncertain etiology. These rare benign fibrous lesions were originally described as "childhood fibrous pseudotumor with psammoma bodies" in two and 11 year old girls by Rosenthal and Abdul-Karim in 1988, from Case Western University, Ohio, USA. ${ }^{12}$ The term calcifying fibrous pseudotumor was coined by Fetsch et al. in 1993. ${ }^{1}$ This name was given thinking that the condition was probably reactive in nature. But now they are believed to be true neoplasms with a tendency for nondestructive local recurrence. ${ }^{11}$

The cause and pathogenesis of this condition is

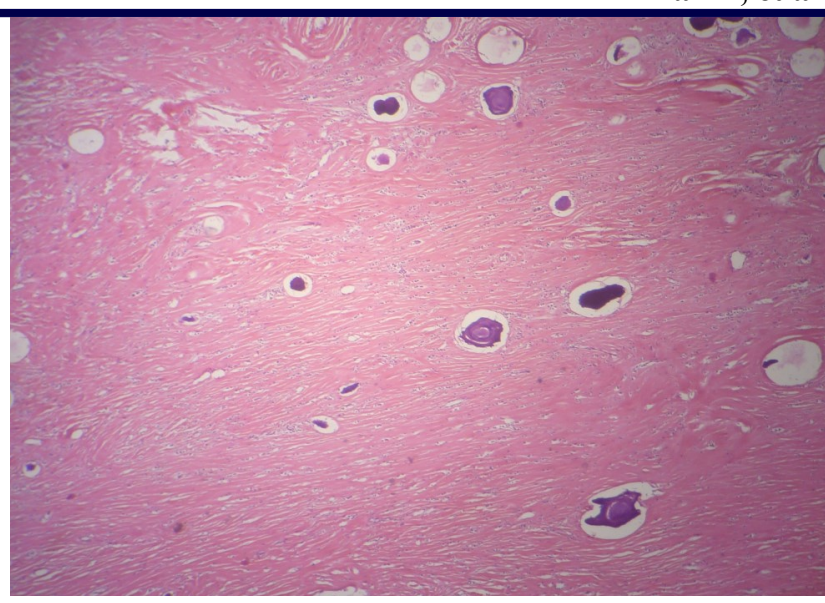

Fig 3: Hypocellular collagen bundles, dystrophic and metastatic calcifications (H and E, 40X)

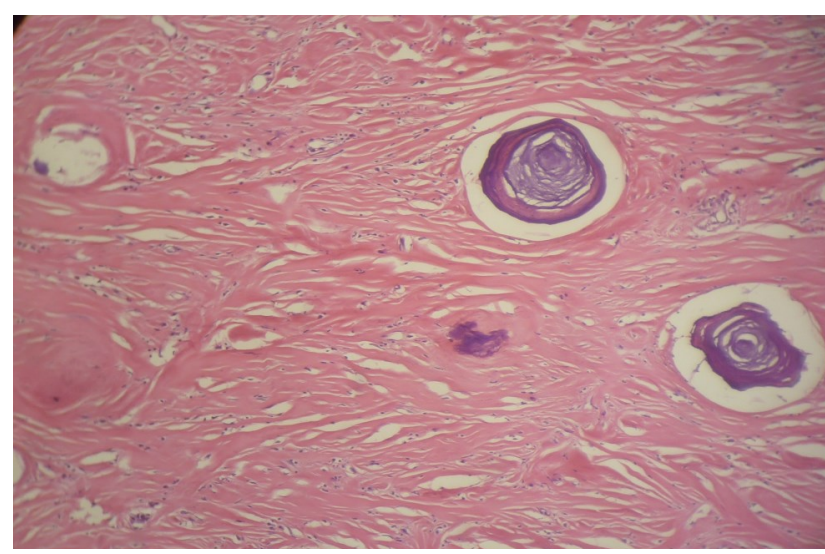

Fig 4: Psammomatous calcifications, chronic inflammatory infiltrate, collagen bundles (H and E, 100X)

unclear but a possible relationship with inflammatory myofibroblastic tumor has been proposed. $^{9}$ However, some larger studies have failed to demonstrate such relationship..$^{11,13}$

These tumors were initially described in soft tissues of extremities, but now have been reported in various sites like neck, scrotum, mesentry, peritoneum, pleura, retroperitoneum and gastrointestinal tract. ${ }^{1-8}$ Most of the lesions are solitary but few multifocal lesions are reported especially in peritoneum and pleura. ${ }^{3,}$ 4, 8-11 However, very few are reported arising from retroperitoneum and multifocal CFT arising from retroperitoneum has not been reported so far. ${ }^{5,11}$

Grossly, the tumor presents as well circumscribed but unencapsulated mass with variable size which may infiltrate into surrounding tissue ranging in size from $<$ one to $15 \mathrm{~cm}^{2}$ Microscopically, the tumor is characterized by scattered fibroblasts, dense collagenization, abundant dystrophic and psammomatous calcifications and focal lymphoplasmacytic aggregates. ${ }^{1,} \quad 2 \quad$ The histopathological differential diagnosis of this entity 
includes conditions like fibromatoses, calcifying aponeurotic fibroma, inflammatory myofibroblastic tumor, collagenous fibroma and retroperitoneal fibrosis in cases arising from retroperitoneum. ${ }^{2,5}$ Fibromatoses and calcifying aponeurotic fibroma are more cellular. ${ }^{2}$ CFT though, thought to be a late sclerotic stage of inflammatory myofibroblastic tumor, has a distinct immunohistochemical and biological behavior. Collagenous fibroma and retroperitoneal fibrosis lack psammomatous calcifications. ${ }^{5}$ Treatment of choice is surgical excision. The condition is benign with rare recurrence and malignant transformation is not reported. ${ }^{2,5,10}$

\section{CONCLUSION}

In summary, CFTs are rare soft tissue neoplasms and multifocal occurrence and retroperitoneal location as described above are extremely uncommon. CFT should be thought of differential diagnosis in well circumscribed cases with calcification as the condition is benign and recurrence rate is low.

\section{REFERENCES}

1. Fetsch JF, Montgomery EA, Meis JM. Calcifying fibrous pseudotumor. Am J Surg Pathol. 1993 May;17(5):502-8. DOI: 10.1097/00000478-199305000-00010.

2. Nascimento AF. Calcifying fibrous tumor. In: Fletcher CDM, Bridge JA, Hogendoorn PCW, Mertens F, editors. WHO Classification of Tumors of Soft Tissue and Bone. 4th ed. France: International Agency for Research on Cancer; 2013. p.69.

3. Bajpai J, Rekhi B, Iyer K, Samar A, Mahajan A, Jambhekar NA. Multifocal calcifying fibrous tumor of the mesentery: an unusual case report with literature review and therapeutic implications. J Cancer Res Ther. 2011 Oct -Dec;7(4):500-2. DOI: 10.4103/0973-1482.92022.

4. Chen KT. Familial peritoneal multifocal calcifying fibrous tumor. Am J Clin Pathol. 2003 Jun;119(6):811-5. DOI: 10.1309/MXC6TWELUUH420W0.

5. Jaiswal SS, Agrawal A, Sahai K, Nair SK. Large retroperitoneal calcifying fibrous tumor. Med J Armed Forces India. 2013 Apr;69(2):184-6. DOI: 10.1016/ j.mjafi.2012.02.008.

6. Agaimy A, Bihl MP, Tornillo L, Wunsch PH, Hartmann A, Michal M. Calcifying fibrous tumor of the stomach: clinicopathologic and molecular study of seven cases with literature review and reappraisal of histogenesis. Am J Surg Pathol. 2010 Feb;34(2):271-8. DOI:10.1097/ PAS.0b013e3181ccb172.

7. Emanuel P, Qin L, Harpaz N. Calcifying fibrous tumor of small intestine. Ann Diagn Pathol. 2008 Apr;12(2):138-41. DOI: 10.1016/j.anndiagpath.2006.08.006

8. Mito K, Kashima K, Daa $\mathrm{T}$, Kondoh $\mathrm{Y}$, Miura $\mathrm{T}$, Kawahara K, et al. Multiple calcifying fibrous tumors of the pleura. Virchows Arch. 2005 Jan;446(1):78-81. DOI: 10.1007/s00428-004-1148-4.

9. Van Dorpe J, Ectors N, Geboes K, D'Hoore A, Sciot R. Is calcifying fibrous pseudotumor a late sclerosing stage of inflammatory myofibroblastic tumor? Am J Surg Pathol. 1999 Mar;23(3):329-35. DOI: 10.1097/00000478199903000-00013.

10. Farah RB, Dimet S, Bidault AT, Benbraheim C, Ndiaye N, Lazure $\mathrm{T}$, et al. Multiple peritoneal calcifying fibrous tumors revealed by ischemic colitis. Ann Diagn Pathol. 2007 Dec;11(6):460-3. DOI: 10.1016/ j.anndiagpath.2006.06.004.

11. Nascimento AF, Ruiz R, Hornick JL, Fletcher CD. Calcifying fibrous 'pseudotumor': clinicopathologic study of 15 cases and analysis of its relationship to inflammatory myofibroblastic tumor. Int J Surg Pathol. 2002 Jul;10 (3):189-96. DOI: $10.1177 / 106689690201000304$.

12. Rosenthal NS, Abdul-Karim FW. Childhood fibrous tumor with psammoma bodies. Clinicopathologic features in two cases. Arch Pathol Lab Med. 1988 Aug;112(8):798-800.

13. Sigel JE, Smith TA, Reith JD, Goldblum JR. Immunohistochemical analysis of anaplastic lymphoma kinase expression in deep soft tissue calcifying fibrous pseudotumor: evidence of a late sclerosing stage of inflammatory myofibroblastic tumor? Ann Diagn Pathol. 2001 Feb;5(1):10-4. DOI: 10.1053/adpa.2001.21474. 